
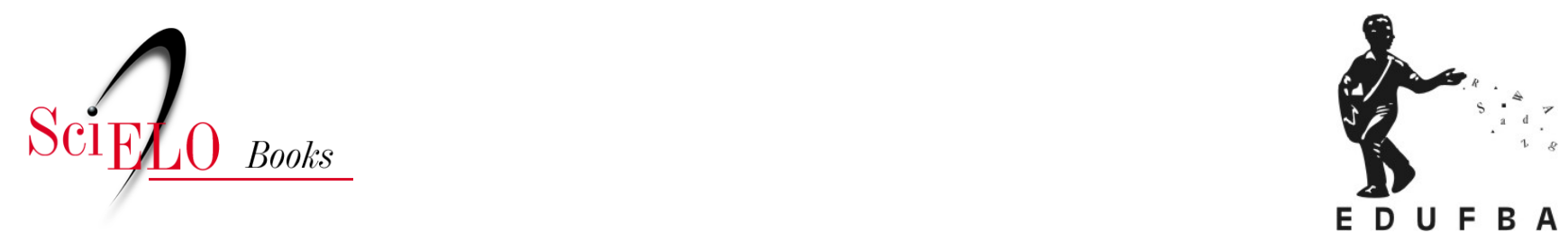

\title{
Política de Sangue no Brasil: \\ desafios e iniciativas para a sua integração na rede de atenção à saúde
}

\author{
Mariluce Karla Bomfim de Souza \\ Glauciene Analha Leister \\ Júnia Guimarães Mourão Cioffi \\ Cláudio Medeiros Santos \\ Helder Teixeira Melo
}

\section{SciELO Books / SciELO Livros / SciELO Libros}

SOUZA, M.K.B., LEISTER, G.A., CIOFFI, J.G.M., SANTOS, C.M., and MELO, H.T. Política de Sangue no Brasil: desafios e iniciativas para a sua integração na rede de atenção à saúde. In: SOUZA, M.K.B., comp. Planejamento e gestão em saúde: caminhos para o fortalecimento das hemorredes [online]. Salvador: EDUFBA, 2018, pp. 45-72. ISBN 978-85-232-2027-3.

https://doi.org/10.7476/9788523220273.0004. \section{International license.}

All the contents of this work, except where otherwise noted, is licensed under a Creative Commons Attribution 4.0

Todo o conteúdo deste trabalho, exceto quando houver ressalva, é publicado sob a licença Creative Commons Atribição 4.0. 


\title{
Política de Sangue no Brasil: desafios e iniciativas para a sua integração na rede de atenção à saúde
}

\author{
Mariluce Karla Bomfim de Souza \\ Glauciene Analha Leister \\ Júnia Guimarães Mourão Cioffi \\ Cláudio Medeiros Santos \\ Helder Teixeira Melo
}

\section{Resgatando a compreensão sobre política de saúde}

A discussão sobre uma política de saúde requer o resgate dos seus conceitos básicos para entendê-la. A palavra política está relacionada a polis que quer dizer "cidade ou comunidade organizada e composta por cidadãos (politikos)". O termo política pode ser considerado sob diferentes pontos de vista, por exemplo, enquanto "prática restrita aos que atuam no âmbito das instituições políticas" ou "o que perpassa as relações sociais e diz respeito a todo e qualquer indivíduo”. (PINTO; VIEIRA-DA-SILVA; BAPTISTA, 2014, p. 69, grifo do autor)

A política como expressão da atuação dos estados remete às concepções de políticas públicas e políticas sociais, sendo a primeira entendida como ações do Estado voltadas para o interesse público/coletivo e influenciada pela economia, regime social, visão dos governantes e atuação dos grupos so- 
ciais, e a segunda, enquanto políticas que os governos desenvolvem voltadas para o bem-estar e a proteção social. (FLEURY; OUVERNEY, 2012)

A política de saúde pode ser entendida como política pública e também política social, e, portanto, como resposta social a problemas e necessidades de saúde. Desse modo, pode ser caracterizada pela ação ou omissão de uma organização (Estado), enquanto resposta social, diante dos problemas e necessidades de saúde e seus determinantes (sociais, ambientais e culturais), bem como em relação à produção, distribuição e regulação de bens, serviços e ambientes que afetam a saúde dos indivíduos e da coletividade. (PAIM, 2003)

A política de saúde se encontra na interface entre o Estado, a sociedade e o mercado, de modo que se caracteriza por distintos interesses e por múltiplas determinações. Portanto, segundo Fleury e Ouverney (2012) para entendê-la deve-se considerar os seus objetivos e finalidades, as estratégias, as técnicas e planos de ação para implementação da política, os efeitos produzidos nas relações sociais, os espaços que orientam o processo decisório, os diferentes projetos sociais, os marcos institucionais que referenciam e sustentam a política e os valores e referenciais éticos que tal política influencia sobre a vida social.

Embora, desde 1974, Gary Brewer afirmasse que as políticas sofriam determinações que modificavam seu curso, muitos analistas de políticas, inclusive ele, propuseram etapas ou estágios para a compreensão do desenvolvimento de uma política. Nos anos 1990, Howlett e Ramesh sistematizaram em cinco etapas o processo da política pública. Portanto, o ciclo se inicia com a entrada na agenda, sendo a incorporação de problemas na "agenda de governos" o ponto de partida para a elaboração de propostas de políticas públicas e de ação governamental; a formulação da política contemplando as intenções, ações e alternativas para a solução dos problemas; a tomada de decisão caracterizada pelas escolhas políticas (ação ou omissão) para o desenvolvimento das intervenções; a etapa de implementação diretamente relacionada à etapa de formulação, visto que a provável e não rara divisão institucionalizada entre quem elabora e quem implementa denuncia as dificuldades de operacionalização/efetivação da política; e finalmente, o processo de monitoramento dos resultados que define a etapa de avaliação da política.

Este capítulo não pretende fazer a análise de uma política de saúde, mas recuperar alguns aspectos sobre o modo de organização e de "fazer" da polí- 
tica de sangue no Brasil, apontando seus desafios e iniciativas, tendo em vista a perspectiva de sua integração nas redes de atenção à saúde.

\section{Evolução histórica das propostas e ações voltadas para a hematologia e hemoterapia no Brasil}

O desenvolvimento da hemoterapia no Brasil teve início a partir da década de 1940, duas décadas após a revolução científica marcada pela pesquisa do Dr. Karl Landsteiner sobre efeitos aglutinantes e grupos sanguíneos. A possibilidade de exames pré-transfusionais para verificação da compatibilidade sanguínea entre doador e receptor romperam o empirismo da transfusão de sangue, estabelecendo um período científico neste campo. (JUNQUEIRA; ROSENBLIT; HAMERSCHLAK, 2005)

A descoberta dos antígenos de superfície das hemácias que estabelecem os grupos sanguíneos $\mathrm{ABO}$, além do emprego de anticoagulantes, e o aperfeiçoamento de equipamentos de coleta e de transfusão de sangue, trouxeram a oportunidade do surgimento de um novo tipo de estabelecimento de saúde, o Banco de Sangue, que teria a função da estocagem do sangue doado e compatibilização imuno-hematológica entre receptor e sangue doado.

Tais adventos promoveram, a partir da década de 1930, o surgimento dos primeiros bancos de sangue no mundo, sendo o primeiro no Brasil inaugurado em 1941, no Hospital Fernandes Figueira, atualmente pertencente à Fundação Oswaldo Cruz. Em seguida, houve a criação do Banco de Sangue da prefeitura do Distrito Federal, em 1945.

Entretanto, cabe ressaltar que o desenvolvimento e o pioneirismo da hemoterapia brasileira não foram acompanhados por regulamentação estatal, trazendo consequências técnicas e políticas para o setor de saúde. (SARAIVA, 2005) De acordo com Melo (2015) até o ano de 1964, a ausência do poder público e o atraso da regulamentação do setor foram prejudiciais ao desenvolvimento da hemoterapia. Esse período "pré-regulamentar", ressalta Saraiva (2005), levou à expansão dos bancos de sangue privados e à comercialização dos produtos hemoterápicos, implicando sobre os processos de doação de sangue, que era então, remunerada, com o sangue comercializado livremente. Na verdade, foram praticamente nulos os esforços de controle da atividade hemoterápica no Brasil até 1964. (SANTOS; MORAES; COELHO, 1991) 
Nesta época, debatia-se acerca da doação voluntária e altruísta em contraponto à doação remunerada, com fins de lucro. Não havia, ainda, uma consciência acerca da necessidade de políticas efetivas para a atenção hematológica e hemoterápica. Como recurso terapêutico cada vez mais difundido, o sangue passou a despertar os interesses do mercado. (PONTES apud SANTOS; MORAES; COELHO, 1991)

Contíguo à realização do primeiro evento científico relacionado ao tema em 1949 à criação, no mesmo ano, da Associação dos Doadores Voluntários de Sangue no Rio de Janeiro e da Fundação da Sociedade Brasileira de Hematologia e Hemoterapia, em 1950, o governo federal sancionou a Lei ${ }^{\circ} 1.075$, de 27 de março de 1950, que Santos, Moraes e Coelho (1991) ressaltam ser a primeira lei no Brasil sobre a doação voluntária de sangue; e, a primeira citação legal sobre a temática de sangue no Brasil. (MELO, 2015) Guerra (2005) ressalta que esta lei teve por objetivo valorizar a doação voluntária de sangue em um período em que era comum a escassez de doadores. Por força deste ato normativo, a doação voluntária de sangue passou a representar ato nobre e relevante para a sociedade e para o Brasil quando realizada em banco de sangue estatal. (BRASIL, 1950) Passada mais de uma década, surgiu outra normativa relacionada à doação nos termos do Decreto ${ }^{\circ} 53.988 / 1964$, que instituiu o dia nacional do doador voluntário de sangue.

Ainda que pioneiros no ordenamento jurídico da hemoterapia, a lei e o decreto supracitados não representaram formulação política mais expressiva ou orientação técnica (MELO, 2015) que trouxessem impacto para a área. Entre a publicação da Lei ${ }^{\circ} 1.075$, em 1950, e a primeira metade da década de 1960 não houve avanços normativos maiores na esfera federal, sobre a hematologia e a hemoterapia.

Em 1960, o tema avançou com a publicação da Lei n ${ }^{\circ}$ 4.701, de 28 de junho de 1965 (BRASIL, 1965), que inicialmente trouxe uma proposição legal oriunda de um grupo de trabalho idealizado pelo Poder Executivo Federal, por ação da Comissão Nacional de Hemoterapia (CNH), que havia sido constituída por meio do Decreto ${ }^{\circ} 54.494 / 1964$. A CNH tinha como objetivo estudar e propor a legislação disciplinadora da hemoterapia no Brasil, estabelecendo as bases para uma Política Nacional de Sangue e a estruturação de um órgão gestor para o gerenciamento nacional da política de sangue. (MELO, 2015) 
Ainda no final desta década, em 1969, foi proposto o modelo hemoterápico brasileiro através do relatório do Dr. Piérre Cazal (OPAS) que propunha a implantação de uma Política Nacional de Sangue através de um sistema de hemocentros descentralizados. (CAZAL, 1969; SANTOS; MOARES; COELHO, 1991)

Em 1980, foi publicada a Portaria Interministerial $\mathrm{n}^{\circ} 7$ - Ministério da Saúde/ Ministério da Previdência e Assistência Social (MS/MPAS) - que estabeleceu o Programa Nacional de Sangue e Hemoderivados (Pró-Sangue), importante avanço da área. Sampaio (2013) destaca que o Pró-Sangue foi de fundamental importância para o avanço da área de sangue no país, no sentido de estruturar e expandir para o interior do país uma rede de serviços de hemoterapia (hemorrede), com o objetivo de alcançar a cobertura hemoterápica em todo o país, utilizando, para isso, a doação voluntária de sangue, a qualificação de recursos humanos e a padronização dos procedimentos técnicos.

Na mesma década do surgimento do Pró-Sangue no Brasil, e desde 1983 com a implantação das Ações Integradas de Saúde (AIS), ${ }^{1}$ os hemocentros seguiram com o programa de extensão da rede hemoterápica apoiados pelas Secretarias Estaduais de saúde e pelo Ministério da Saúde. (BARCA, 2013)

Desde a concepção dos hemocentros públicos, a atenção às pessoas com coagulopatias hereditárias, ${ }^{2}$ principalmente as hemofilias, se caracterizava como uma de suas diretrizes. As pessoas compareciam diariamente aos serviços de hemoterapia para o tratamento hemoterápico, pela necessidade de transfusão para realizar as terapias de reposição de fatores. Nesta época, o tratamento de reposição aos hemofílicos era realizado principalmente com o Plasma Fresco Congelado e Crioprecipitado e, esporadicamente, concentrados de fator de coagulação liofilizado.

Ainda na década de 1980, alguns eventos e descobertas impulsionaram o direcionamento do interesse das autoridades para a melhoria da Política

1 As AIS, instituídas de acordo com as orientações e pressupostos do plano Conselho Consultivo de Administração Previdenciária (Conasp), constituíam uma "estratégia de integração programática entre as organizações de saúde de nível federal, estadual e municipal” (CASTRO; VIANA, 1992 apud PUGIN; NASCIMENTO, 1996, p. 13), e que incluía também os diversos prestadores de serviços nas três esferas.

2 As coagulopatias hereditárias, decorrentes da deficiência de um ou mais fatores da coagulação sanguínea, são caracterizadas pela ocorrência de distúrbios hemorrágicos cuja gravidade varia de forma espontânea e/ou traumática. (BRASIL, 2012) 
de Sangue e da Política de Atenção aos Hemofílicos, como o agravante dos novos casos da Síndrome de Imunodeficiência Adquirida (AIDS) no país, marcada em 1981 principalmente pelo conhecimento da via transfusional como importante fonte de transmissão, com a constatação de que $2 \%$ dos casos de AIDS eram transmitidos por transfusão e que $50 \%$ dos hemofílicos apresentavam-se contaminados pelo HIV. (RIBEIRO, 2007) Na ocasião, já se considerava que o atendimento às pessoas com coagulopatias deveria ser multidisciplinar, com abordagens fisioterápicas, ortopédicas, odontológicas, psicológicas, dentre outras.

A preocupação com a transfusão de HIV/AIDS foi expressa por meio de ato legislativo - Lei $n^{\circ} 7.649 / 1988$, publicado no mesmo ano da promulgação da Constituição Federal Brasileira (CF/88) e da garantia da saúde enquanto direito mediante o SUS. A referida lei estabeleceu o cadastramento obrigatório dos doadores de sangue e a realização de exames laboratoriais no sangue coletado, a fim de prevenir o desenvolvimento e proliferação de doenças. (MELO, 2015) O temor com a propagação de doenças por meio do agente curativo da hemoterapia, em especial para os pacientes que faziam transfusões frequentes e regulares dos hemocomponentes, fez com que o tema das infecções transmissíveis por transfusão ampliasse significativamente o controle sanitário e a regulamentação do setor.

Ainda, quanto a atenção pessoas com coagulopatias, devido às suas características, complexidades e complicações, os hemocentros, ao longo do tempo, buscaram se estruturar para ofertar o cuidado multidisciplinar e integral no próprio Serviço de Hematologia e Hemoterapia (SHH), ora se aproximando e ora se distanciando dos demais equipamentos de saúde disponíveis no SUS.

Quanto à atenção às pessoas com hemoglobinopatias, cabe ressaltar que foi absorvida pelos hemocentros no final da década de 1980. Pessoas com doença genética hematológica, com várias intercorrências clínicas e alta morbidade e mortalidade, não conseguiam atendimento especializado na rede do SUS e passaram a ter os mesmos cuidados disponibilizados para os pacientes com coagulopatias dentro dos hemocentros. (CIOFFI; MURAO, 2007)

Estimulada pelos movimentos sociais, em 1996 foi publicada, pelo Ministério da Saúde, a Portaria GM/MS n 951, de 10 de maio de 1996, que instituiu grupo de trabalho para elaborar o Programa Nacional de Doença Falciforme. 
(BRASIL, 1996) A primeira política pública direcionada para Doença Falciforme foi em 2001, através da Portaria GM/MS nº 822, de 6 de junho de 2001, quando foi instituído o Programa Nacional de Triagem Neonatal, ${ }^{3}$ para detecção de quatro doenças congênitas no período neonatal, incluindo as Hemoglobinopatias. (MÁXIMO, 2009) Este programa foi elaborado com base em programas estaduais que já em andamento, com resultados que evidenciavam a importância de uma política voltada para esta população com doença de alta morbidade e mortalidade.

A Organização Mundial da Saúde (OMS) orienta os países membros que seus respectivos Ministérios da Saúde devem proporcionar uma liderança eficaz e governança no desenvolvimento de um sistema nacional de sangue totalmente integrado ao sistema de saúde. A organização considera que a atenção hemoterápica, em um país, deve prover de forma responsável a segurança transfusional e a disponibilidade de sangue e derivados, considerando esta pauta como problema de saúde pública. (ORGANIZAÇÃO MUNDIAL DA SAÚDE, 2014 apud MELO, 2015)

O marco governamental que demonstra esse compromisso e as responsabilidades, dos agentes públicos envolvidos com a segurança e disponibilidade dos produtos hemoterápicos, expressou-se na Lei n ${ }^{\circ} 10.205$, de 21 de março de 2001 que regulamentou o artigo 199 da CF88, abordando sobre a coleta, processamento, estocagem e distribuição de sangue e hemoderivados e estabeleceu o ordenamento institucional para a execução de tais atividades. (BRASIL, 2001b)

Esta lei dispôs sobre a Política Nacional de Sangue, Componentes e Hemoderivados e determinou a garantia da autossuficiência e harmonização das ações do poder público em todos os níveis de governo, dentre outras coisas. O capítulo que trata da direção e gestão, refere que a execução da política nacional caberá ao Sistema Nacional de Sangue, Componentes e Derivados (Sinasan), que atuará observando vários postulados, e acrescenta, em seu artigo 17, que aos estados, Distrito Federal e Municípios, por meio de suas secretarias de saúde ou equivalentes, caberão a coordenação da execução das

3 O Programa de Triagem Neonatal (PNTN), com triagem para a identificação das hemoglobinopatias (Fase 2) foi instituído através da Portaria $n^{\circ} 822 / 2001$. Entretanto, vale destacar que a triagem neonatal já havia sido criada, desde 15 de janeiro de 1992, com testes para detecção precoce de fenilcetonúria e hipotireoidismo congênito (Fase 1). (CANÇADO; JESUS, 2007) 
ações correspondentes do Sinasan no seu âmbito de atuação, em articulação com o Ministério da Saúde. (BRASIL, 2001b)

O artigo 10 da Lei $n^{\circ}$ 10.205/2001 confere observância dos princípios e diretrizes do SUS à Hematologia e Hemoterapia, inclusive no que se refere à busca da equidade, da integralidade do cuidado, da acessibilidade às ações e serviços, da descentralização político-administrativa, da capacidade de resolubilidade dos serviços e da organização dos serviços a fim de evitar a duplicidade de meios para fins idênticos, dentre outros, como disposto na Lei $\mathrm{n}^{\circ} 8.080$, de 19 de setembro de 1990. (BRASIL, 1990)

Também, no ano de 2001, foram publicados o Decreto n 3990/2001 e a Resolução da Diretoria Colegiada $n^{\circ} 151$. O decreto, dentre outras determinações, tratou das competências dos entes federativos na implementação da Política de Sangue e Hemoderivados, com atribuições diversas, com ênfase na regionalização, na garantia do acesso da população de sua área de abrangência à assistência hemoterápica, na garantia da assistência à saúde dos portadores de doenças hematológicas, conforme pactuações do Estado, por meio de referências e contrarreferências, bem como outras atribuições voltadas para vigilância, planejamento, gestão de pessoas, gestão da informação e financiamento para a melhoria da qualidade do sangue. (BRASIL, 2001a)

A Resolução de Diretoria Colegiada (RDC) no 151 Anvisa/MS apresentava o modelo de conformação técnica e administrativa da Hemorrede brasileira, a ser estruturada em cada unidade federativa, sendo constituída pelos seguintes serviços: um Hemocentro Coordenador (HC), situado na capital do estado; Hemocentros Regionais (HR) e Núcleos de Hemoterapia (NH) estrategicamente distribuídos na extensão territorial de cada estado; Unidades de Coleta e Transfusão (UCT), Unidades de Coleta (UC) e Central de Triagem Laboratorial de Doadores (CTLD), opcionais e a depender da capacidade técnica e operacional da cada estado; e, as Agências Transfusionais (AT), de menor densidade tecnológica. (AGÊNCIA NACIONAL DE VIGILÂNCIA SANITÁRIA, 2001)

Ao longo do tempo, várias normatizações foram dando estruturação jurídica para o desenvolvimento das ações e serviços da Hemorrede no Brasil. No que se refere à atenção às pessoas com coagulopatias, cabe destacar o ato normativo publicado, RDC n ${ }^{\circ} 10$ de 23 de janeiro de 2004, pela Anvisa, resolução que limitou o uso de Plasma Fresco Congelado (PFC) às pessoas com coagulopatias adquiridas, contraindicando o seu uso para os casos de Hemofília, 
exceto quando se comprovasse o risco de vida e a falta de hemoderivados. (AGÊNCIA NACIONAL DE VIGILÂNCIA SANITÁRIA, 2004)

A determinação do uso de hemoderivados para as pessoas com coagulopatias, a aquisição permanente de concentrado de fatores de coagulação pelo Ministério da Saúde e a possibilidade do fracionamento de PFC excedente para produção de hemoderivados foram importantes marcos que promoveram a melhoria da qualidade de vida às pessoas com Hemofilia e que, ao mesmo tempo, evidenciaram a necessidade dos serviços disponibilizarem atenção integral, ofertando, dessa forma, cuidado para além do tratamento medicamentoso exigindo, portanto, o envolvimento e a articulação dos diversos pontos das Redes de Atenção do SUS. Diferentemente da Atenção às pessoas com Doença Falciforme, não há uma Política de Atenção Integral às pessoas com coagulopatias, mas sim publicações de protocolos ${ }^{4}$ que orientam o tratamento dos pacientes hemofílicos, o que aponta a necessidade de orientações/diretrizes para a organização dos serviços em rede.

$\mathrm{Na}$ atenção às pessoas com hemoglobinopatias, destaca-se a Portaria Ministerial $n^{\circ} 1.391$, de 16 de agosto, publicada em 2005, que estabelece no âmbito do SUS, as diretrizes para a Política Nacional de Atenção Integral às Pessoas com Doença Falciforme e outras Hemoglobinopatias, com o objetivo de mudar a história natural da doença no Brasil a partir da redução da morbimortalidade e melhoria da qualidade de vida. (BRASIL, 2005) O inciso II do artigo primeiro desta portaria, ao estabelecer a promoção da garantia da integralidade da atenção por equipe multidisciplinar e as interfaces entre as diferentes áreas técnicas do Ministério da Saúde para a articulação das demais ações que extrapolam a competência da Hemorrede, direciona as ações dos gestores às premissas do Pacto pela Saúde (BRASIL, 2005) de integração das ações de promoção à saúde e das ações da Atenção Básica, média e alta complexidade/densidade tecnológica.

$\mathrm{Na}$ Atenção Hemoterápica foram diversos os avanços alcançados para a melhoria da qualidade dos hemocomponentes ao longo dos anos. De acordo com o Relatório Anual de Vigilância Sanitária, de 2015, 92,23\% dos 888 serviços de hemoterapia avaliados em 2014 se encontravam em situação con-

4 Em 2014 foram publicadas as portarias $n^{\circ} 364$ e a n 478 com protocolos para uso de indução de imunotolerância para pacientes com hemofilia A e inibidor e para uso de profilaxia primária para hemofilia grave, respectivamente. (BRASIL, 2014a, 2014b) 
siderada satisfatória, entre baixo e médio risco potencial. Entre 2012 a 2014, observou-se redução do risco sanitário pela diminuição dos percentuais de estabelecimentos classificados nas categorias de médio, médio alto e alto risco potencial, o que aponta evolução favorável da qualidade das ações e produtos hemoterápicos, resultado de investimentos técnicos e gerenciais realizados pelos diversos atores envolvidos no aperfeiçoamento da segurança transfusional. Destaca-se como importante estratégia que influenciou na melhoria da qualidade dos SHH, o Programa Nacional de Qualificação da Hemorrede (PNQH) e o Programa Estadual de Qualificação da Hemorrede (PEQH) que permitem a identificação de cenários nos SHH e têm sido considerados potentes estratégias para apontar oportunidades de melhorias técnicas e gerenciais na Hemorrede e para promover o aperfeiçoamento dos processos de trabalho na premissa da gestão da qualidade, com o intuito de possibilitar diagnóstico situacional da Hemorrede e orientar o desenvolvimento de ações visando ao aumento da segurança transfusional para todos os serviços do país. (BRASIL, 2016)

Apesar dos êxitos obtidos para Atenção Hematológica e Hemoterápica, ainda persistem entraves importantes em todo país, especialmente em regiões que historicamente sofrem iniquidades sociais, desde dificuldade de acessibilidade às ações e aos serviços de saúde até atendimento em tempo oportuno das necessidades identificadas.

\section{A Política de Sangue e o desafio para o fortalecimento da Hemorrede}

O modelo estabelecido para o Sistema Nacional de Sangue, Componentes e Derivados (Sinasan) em 2001, fazia a transição da perspectiva da governança e responsabilidade dos estados para o âmbito federal na hemoterapia. (HOGAN; GARGARELLA, 1997) Tal situação parece decorrer da percepção de que o Ministério da Saúde deveria assumir maior liderança no desenvolvimento da política de sangue e hemoderivados para todo o sistema do Brasil, frente as carências percebidas no setor.

Com ampliação da demanda por atendimento hematológico e hemoterápico aos serviços de abrangência SUS e também com a ampliação do escopo da atenção aos portadores de hemoglobinopatias e coagulopatias, as hemor- 
redes estaduais foram se estruturando de forma diferenciada, ajustando-se às conjunturas locais e estruturais. Constituiu-se como desafio à gestão da hematologia e hemoterapia nas três esferas de governo a condução da política nacional de sangue nas instâncias de pactuação interfederativa do SUS, bem como a inclusão de ações e proposições da Hemorrede em metas políticas nas agendas governamentais.

Atualmente, observam-se hemorredes estaduais com fragilidades importantes de articulação entre os seus SHH. Em 2001, na tentativa de padronização das Hemorredes, foi publicada a RDC151, de 21 de agosto de 2001. (AGÊNCIA NACIONAL DE VIGILÂNCIA SANITÁRIA, 2001) Esta RDC definiu os níveis de complexidade dos serviços de hemoterapia, mas não abordou a complexidade relacionada ao atendimento das pessoas com coagulopatias e hemoglobinopatias. Apesar de ser muito utilizada para o cadastramento dos serviços de hemoterapia, públicos e privados, municipais ou estaduais pelas Vigilâncias Sanitárias, é possível concluir a necessidade de atualizações para compatibilização da norma com as estruturas agora existentes, tanto para a hemoterapia, quanto para a hematologia.

Uma importante ferramenta à organização da Hemorrede e para o enfrentamento das dificuldades apontadas é a formulação dos planos diretores nacional e estaduais de sangue, componentes e derivados, previstos no Decreto $\mathrm{n}^{\circ}$ 3.990/2001, Art. $4^{\circ}$, inciso XIII. Tais planos são fundamentais para orientar estados, municípios e o Distrito Federal na execução de ações e estratégias no setor, permitindo a definição de parâmetros assistenciais, ou ainda, acompanhar e avaliar o cumprimento das metas políticas locais para a área do sangue, componentes e derivados.

Ao colocar o usuário do SUS como indivíduo que deve ser efetivamente considerado no desenho da atenção integral e tendo em vista que em muitas regiões do país os SHH não comportam toda a oferta de cuidado necessária, torna-se fundamental o estreitamento e a oficialização das negociações das ações com os demais gestores do SUS, bem como com os usuários do sistema, inclusive no que se refere às pactuações referentes ao redesenho de rede e até mesmo a ampliação de serviços. A Política de Sangue deve ser conhecida por todos os agentes do processo, inclusive por ser estratégica, permeando tanto a atenção hospitalar quanto a ambulatorial. Discussões habituais do sistema, como ampliação de leitos de terapia intensiva ou referenciamento de cirurgias 
para determinado município deve levar em conta a estrutura locorregional da hemorrede. Estes e outros motivos impulsionam a importância do papel da hemorrede na condução/pactuação regional das políticas do SUS, tanto nas que envolvem diretamente a hematologia e hemoterapia, quanto na necessidade das hemorredes ampliarem sua interlocução com os demais segmentos.

Segundo Cândido e Abreu (2000), citados por Bastos e Souza (2014, p. 16), uma hemorrede constitui-se como uma rede de serviço de saúde com característica intraorganizacional, constituída por departamentos e setores que mantêm trocas e interações entre si, com características de flexibilidade, horizontalização e descentralização. A organização da hemorrede prevê a otimização de recursos financeiros e equipes de trabalho qualificadas para o desenvolvimento das atividades e o compartilhamento dos problemas.

As hemorredes estaduais no Brasil se caracterizam pela forma diversa de gestão e organização dos serviços que a constituem, em muitos destes estados sua organização encontra-se descentralizada e regionalizada (BASTOS; SOUZA, 2014; SOUZA; VIANA, 2014), constituída por serviços do setor público e privado (SILVA; SOARES; IWAMOTO, 2009), e por uma rede interorganizacional representada por contratos com clínicas e hospitais da mesma região ou de outras próximas que consomem produtos da hemorrede. (GRAMKOW, 2002)

Considerando, portanto, a complexidade da hemorrede que deve estar organizada e sustentada nos princípios da Política do Sangue, haja vista a sua conformação diversa, destacam-se também a universalidade de sua abrangência, já que se almeja cobertura hemoterápica 100\% pública, a despeito do seu atendimento público e privado, bem como a transversalidade de sua atuação, pois o hemocomponente é considerado produto estratégico para outras ações de saúde, como urgência e emergência, procedimentos cirúrgicos, desde os mais simples até os mais complexos, como transplantes, etc.

Um importante tema relacionado ao fortalecimento da Política de Sangue, diz respeito ao financiamento das atividades hemoterápicas e da assistência hematológica. Vetado na Lei $\mathrm{n}^{\circ} 10.205 / 2001$, o tema permanece ausente da discussão normativa específica do setor, restringindo-se o financiamento da hemoterapia ao repasse de teto de transferência de recursos federais e ao ressarcimento de produção na Hemorrede, pelo modelo de tabela de procedimentos do SIA/SIH/SUS. 
A aprovação da Emenda Constitucional $n^{\circ} 29$, que determina valores de aporte pelas instâncias federal, estaduais e municipais, apresentou possibilidades para o financiamento do setor; e, as portarias $\mathrm{n}^{\circ} 1.737$ de 19 de agosto de 2004 e $^{\circ} 1.469$ de 10 de julho de 2006 trouxeram a possibilidade da Hemorrede obter ressarcimento dos serviços prestados fora do âmbito do SUS, com o direcionamento da ampliação da cobertura pelos serviços públicos; porém, ainda existe gargalo no financiamento da Hemoterapia no país. Tal questão deve ser abordada de forma especial nas discussões sobre planejamento do setor, e até mesmo do redesenho de um modelo mais apropriado ao financiamento dos altos custos da hemoterapia no Brasil e no mundo.

\section{(Re)conhecendo a rede de atenção à saúde e os desafios para a integração da política do sangue}

Após mais de duas décadas desde o surgimento do SUS e, considerados os avanços alcançados, muitos entraves e lacunas ainda existem para a sua consolidação nos termos da constituição. Dentre as lacunas ainda persistentes no SUS, destaca-se a intensa fragmentação das ações e serviços de saúde. (BRASIL, 2006a) Embora exista robusto arcabouço jurídico e normativo, que ampara a organização do sistema de saúde e instrumentaliza os gestores do SUS nas suas áreas de abrangência, muitas têm sido as dificuldades e os desafios para a operacionalização de uma atenção integral.

Assumir os princípios e diretrizes do SUS nas práticas de saúde pressupõe compreendê-los na sua complexidade e reconhecer que de fato é um desafio realizar gestão, assistência e pesquisa em conformidade com todas essas premissas, visto que há uma grande gama de variáveis que influenciam o alcance dos resultados, incluindo a dificuldade de acessibilidade às ações e aos serviços de saúde; entraves com relação ao financiamento; (des)articulação entre os pontos de atenção das Redes de Atenção à Saúde (RAS); problemas nos sistemas logísticos e de apoio, na governança dos serviços, dentre outros.

Nesse contexto e no que se refere à integração das políticas de saúde e de suas ações, há que destacar também o perfil demográfico e etário atual da população, que adquiriu padrão diferente do século passado, apresentando novos desafios para a organização do sistema e dos serviços de saúde. O nú- 
mero de idosos representa um contingente expressivo em termos absolutos e de crescente importância relativa no conjunto da sociedade brasileira, daí decorrendo uma série de novas exigências em termos de políticas públicas e organização do sistema e serviços de saúde. O contexto atual caracteriza-se pela persistência de antigos problemas de saúde pública e o surgimento de novas formas de adoecer e morrer por doenças transmissíveis emergentes e reemergentes, fatos estes que apontam para grandes desafios, especialmente para o setor saúde que demanda mudanças urgentes nas práticas e modos de gestão e organização do sistema de saúde.

Em geral, os problemas de saúde não se distribuem uniformemente e envolvem tecnologias diversas em sua complexidade e custo. Neste sentido, Noronha, Lima e Machado (2012) apontam para a necessidade de organizar uma rede de atenção à saúde no SUS, sendo necessário, para isso, a hierarquização e regionalização das ações e serviços de acordo com as necessidades. Para estes autores, a rede de atenção à saúde representa “[...] o conjunto de estabelecimentos, de diferentes funções e perfis de atendimento, que operam de modo ordenado e articulado no território, de modo a atender as necessidades de saúde de uma população". (NORONHA; LIMA; MACHADO, 2012, p. 369)

Em documento base sobre redes regionalizadas de atenção à saúde publicado pelo Ministério da Saúde, em 2008, constavam os desafios para a conformação e consolidação das redes de atenção, inclusive na proposta de redes regionalizadas. Dentre estes, estavam citados a insuficiência da base de financiamento da política de saúde; a assimetria na distribuição dos serviços; o acesso insuficiente aos serviços de atenção especializada e hospitalar; as limitações na capacidade institucional - recursos financeiros, humanos e técnicos - da maioria dos municípios; a baixa funcionalidade e racionalidade do processo de organização e gestão dos sistemas de saúde em âmbito regional; além da precariedade das relações de vínculo funcional, com elevada rotatividade de profissionais e abordagem reduzida do processo saúde doença cuidado. (BRASIL, 2008)

Para o enfrentamento das dificuldades nas práticas de saúde, estratégias vêm sendo debatidas e operacionalizadas nos serviços de saúde, incluindo ações macro e micropolíticas, bem como a utilização de ferramentas relacionadas às tecnologias duras, leve-duras e leves, que resultem na organização 
de serviços que produzam cuidado singularizado e que considerem as necessidades do usuário para o planejamento das suas ações. (MALTA; MERHY, 2010; MERHY, 1998)

No plano macropolítico, a organização dos serviços em Redes de Atenção à Saúde é uma das estratégias de superação da fragmentação da atenção e da gestão, com o intuito de aperfeiçoar o funcionamento político-institucional do SUS, visando assegurar ao usuário o conjunto de ações e serviços efetivos e eficientes que respondam às necessidades de saúde individuais em âmbitos local e regional. (BRASIL, 2010; HARTZ; CONTANDRIOPOULOS, 2004, p. 331; MENDES, 2010)

A fim de direcionar a conformação das redes de atenção à saúde, em 2010, o Ministério da Saúde publicou a Portaria GM n ${ }^{\circ} 4.279$, de 30 de dezembro de 2010, que considera a estruturação da rede como estratégia para superar a fragmentação da atenção e da gestão nas Regiões de Saúde e aperfeiçoar o funcionamento político-institucional do SUS, com vistas a assegurar ao usuário o conjunto de ações e serviços de que necessita, com efetividade e eficiência. Tal normativa apresenta os diversos atributos da rede, cabendo destacar a definição da população e território, a disposição de diversos estabelecimentos de saúde, os mecanismos de coordenação e integração assistencial, bem como, o sistema de governança, a gestão integrada dos sistemas de apoio administrativo, clínico, logístico e o financiamento. No que se refere às conceituações listadas no referido marco normativo, após destacar que os pontos de atenção de uma rede representam os espaços para oferta de determinados serviços produzidos de forma singular, a portaria delineia exemplos destes espaços destacando, entre outros, os serviços de hematologia e hemoterapia. (BRASIL, 2010)

Reforçando a importância do estabelecimento das redes de atenção e tendo em vista os desafios para sua operacionalização, em 2011, foi publicado o Decreto $n^{\circ} 7.508$, de 28 de junho de 2011, pelo Ministério da Saúde, que dentre outras disposições, enfatizou a estrutura de organização hierarquizada e regionalizada para a operacionalização do SUS, destacou a necessidade do planejamento e articulação interfederativa, e apontou alguns dispositivos como os contratos organizativos de ação pública, as alternativas de portas de entrada, o mapa da saúde, as comissões intergestoras regionais e os protocolos e diretrizes clínicas e terapêuticas. Nas suas disposições 
preliminares conceituou as redes de atenção à saúde como o “[...] conjunto de ações e serviços de saúde articulados em níveis de complexidade crescente, com a finalidade de garantir a integralidade da assistência à saúde”. (BRASIL, 2011)

Para além dos instrumentos normativos, a discussão de RAS também é colocada por muitos autores. Dentre eles, Mendes $(2010,2011)$ cita que as RAS se configuram como organizações poliárquicas de conjuntos de serviços de saúde, vinculados entre si por uma missão única, por objetivos comuns e por uma ação cooperativa e interdependente, que permitem ofertar atenção contínua e integral a determinada população, coordenada pela atenção primária à saúde/atenção básica prestada no tempo certo, no lugar certo, com o custo certo, com a qualidade certa e de forma humanizada, e com responsabilidades sanitárias e econômicas por esta população. Constituídas por três elementos: a população, a estrutura operacional e o modelo de atenção à saúde, as redes de atenção caracterizam-se pela sua complexidade e pelos desafios para sua operacionalização.

Nesse contexto, ao considerar a transversalidade da hematologia e hemoterapia com as diversas áreas da saúde e entendendo que suas práticas e produtos ora se caracterizam como sistema de apoio, ora como ponto de atenção (ver Figura 1) torna-se necessário potencializar as práticas de gestão integrativas em rede para superação das invisibilidades e vazios assistenciais da atenção hematológica e hemoterápica.

As diferenças e particularidades das diversas regiões do país revelam dificuldades variadas que vão desde os níveis estratégicos até os níveis táticos e operacionais, sendo desde problemas macroestruturais até dificuldades técnicas e internas inerentes aos processos de trabalho. Dentre as fragilidades para a integração da Política do Sangue na Rede de Atenção à Saúde, encontram-se deficiências na pactuação e implementação de políticas estaduais para hematologia e hemoterapia, modelo de financiamento insuficiente para as demandas inclusive reprimidas, deficiências em qualificação técnica e gerencial decorrentes de problemas diversos relacionados a força de trabalho e a governança, diversidade na natureza jurídica dos serviços, infraestrutura física e de equipamentos inadequada, dentre outros. 
Figura 1 - Os serviços de hematologia e hemoterapia na estrutura operacional das redes de atenção à saúde

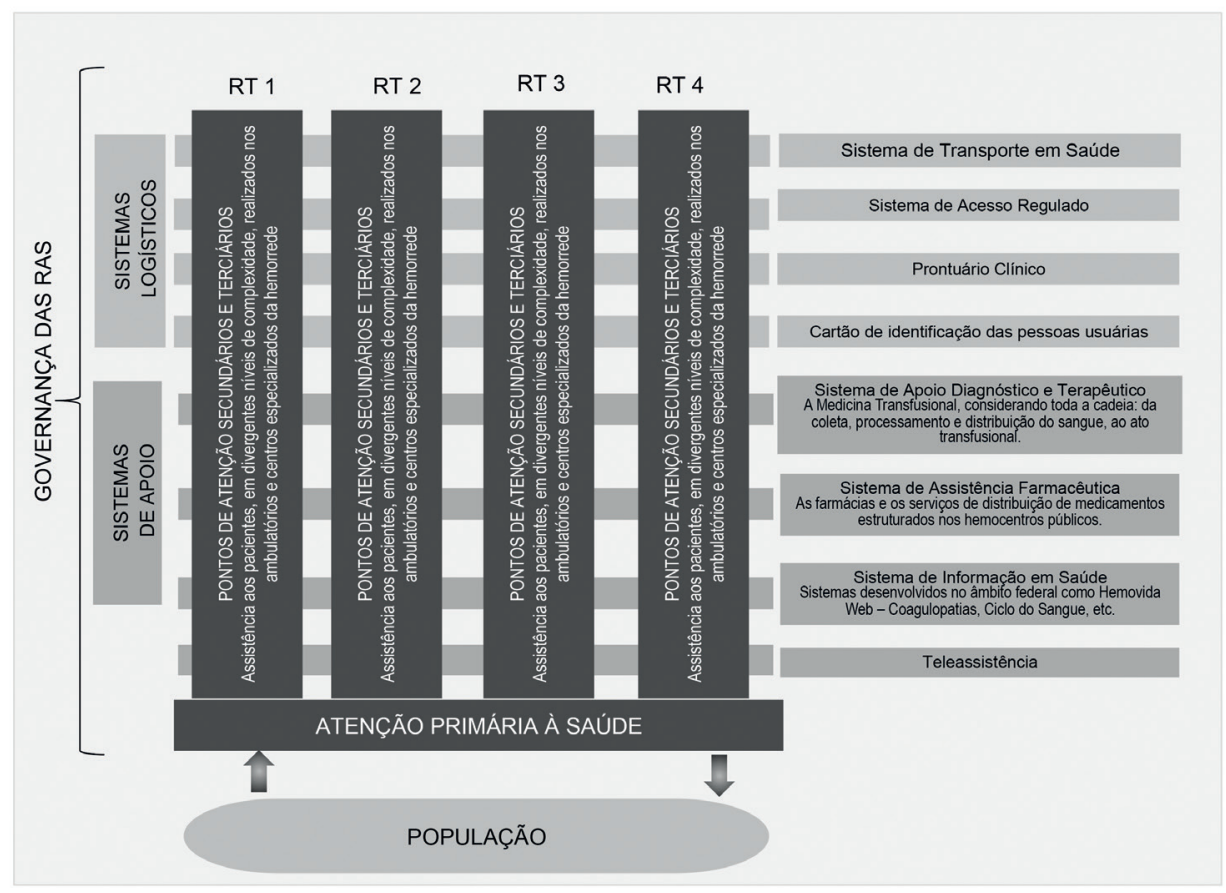

Fonte: elaborada pelos autores com base em Mendes [2011].

\section{Iniciativas e ações estratégicas recentes para o fortalecimento da integração da gestão e das práticas em hematologia e hemoterapia na Rede de Atenção à Saúde}

No sentido de fortalecer as práticas integrativas em rede, o "Planeja Sangue" é importante iniciativa da Coordenação-Geral de Sangue e Hemoderivados do Ministério da Saúde desenvolvido em parceria, desde 2014, com o Instituto de Saúde Coletiva da Universidade Federal da Bahia (ISC/UFBA), que dirige esforços para a incorporação de tecnologias de gestão e mudanças de práticas político-gerenciais no âmbito do sistema público de saúde. O referido projeto visa instrumentalizar os gestores e profissionais envolvidos para o desenvolvimento da capacidade técnica de planejar, assim como estimular o compromisso com a institucionalização local do planejamento em saúde, 
proporcionando, assim, apoio às hemorredes estaduais para a formulação e execução de Planos Diretores de Sangue e Hemoderivados e de planos estratégicos operacionais voltados à gestão dos serviços de hemoterapia; bem como, para a análise e aperfeiçoamento da política estadual para as pessoas com coagulopatias e hemoglobinopatias, de forma a possibilitar a compreensão de que o cuidado dessas pessoas perpassa por todos os níveis de atenção, abrangendo, desse modo, a gestão da política e a gestão dos serviços.

Além disso, propõe-se a estimular o processo de planejamento em saúde de modo articulado, solidário e integrado entre os diversos serviços que compõem o SUS, contemplando as necessidades regionais de cada estado e visando como principal produto o Plano Diretor de Hematologia e Hemoterapia, de maneira a ser pactuado nas instâncias locais do SUS de forma articulada às Redes de Atenção a Saúde e na perspectiva da inserção das necessidades das Hemorredes nas agendas políticas estaduais.

Outra iniciativa importante da gestão federal é o PNQH, como já citado anteriormente, que tem como objetivo aperfeiçoar as atividades dos $\mathrm{SHH}$ com foco na melhoria dos processos, a fim de promover o aumento da segurança transfusional por meio da colaboração mútua da Hemorrede. O programa visa promover a qualidade técnica e gerencial da atenção hematológica e hemoterápica em consonância com os princípios e diretrizes do SUS, no que se refere à constante busca da integralidade, da universalidade e da equidade na disponibilização dos serviços hematológicos e hemoterápicos. Como a abrangência do PNQH se destina principalmente aos hemocentros coordenadores, e considerando a complexidade que envolve a segurança transfusional, foi necessário ampliar o escopo de atuação do programa e implantar a etapa de estadualização, com o PEQH, implantação que foi iniciada em 2011. (BRASIL, 2016) O PEQH tem como objetivo implantar e implementar o programa de qualificação técnica e gerencial na hemorrede estadual/regional, promovendo, assim, o fortalecimento da articulação e da coordenação estadual entre os SHH, visando à conformação em rede dos SHH.

Assim, enquanto o Planeja Sangue promove o envolvimento dos diversos atores sociais da Secretaria Estadual de Saúde, das Vigilâncias, gestores e profissionais dos serviços de hematologia e hemoterapia e dos diversos pontos de atenção, dentre outros no processo de elaboração do Plano Diretor da Hemorrede estadual e, com isso se caracteriza como prática integrativa 
da Hemorrede com os pontos de atenção da RAS, o PEQH consolida-se como potente iniciativa para fortalecer a articulação dos serviços de hematologia e hemoterapia em rede. Dessa forma, embora com ênfase e abrangência diferentes, as estratégias citadas se complementam e se entrelaçam à medida que pretendem promover a disponibilização das ações e serviços aos usuários do SUS de forma articulada e a oferta da atenção hematológica e hemoterápica de modo integral.

Outra iniciativa ou ação estratégica da gestão federal indutora de articulação da Hemorrede com outros pontos de atenção da RAS é a elaboração e o fortalecimento de linhas de cuidado na atenção hematológica e hemoterápica, que tem como exemplo, a Linha de Cuidado às pessoas com Doença Falciforme. (BRASIL, 2015) A Linha de Cuidado é uma proposta de reorganização dos processos de trabalho, com base na organização de fluxos assistenciais capazes de garantir acesso às tecnologias necessárias. Estes fluxos têm o usuário como elemento central e estruturante de todo processo de produção da saúde e opera com base na integralidade e nas necessidades de saúde dos usuários. (FRANCO; MAGALHÃES JÚNIOR, 2004)

Malta e Merhy (2010) ressaltam que a organização do serviço com base em Linhas de Cuidado deve promover ao usuário um "caminhar na rede de serviços" de forma segura e sem obstáculos. Apontam ainda que a linha de produção de cuidado não deve se esgotar no Projeto Terapêutico, mas que deve continuar no acompanhamento deste usuário ao longo do tempo, a fim de garantir a integralidade do cuidado em todos os serviços acessados. Para tanto, os autores salientam a necessária responsabilização tanto da equipe, quanto dos gestores públicos, para que não ocorram a interrupção e a segmentação do cuidado.

A organização de Linhas de Cuidado estimula a utilização de tecnologias leves produtoras de singularizações no cuidado e considera, para o planejamento das ações em saúde, as necessidades do usuário como ponto de partida para a conformação da oferta da atenção em saúde. (MALTA; MERHY, 2010)

A estruturação de Linhas de Cuidado pode ser potente ferramenta de gestão especialmente na Atenção Hematológica, visto que conforme já colocado anteriormente, possibilita, ao ser devidamente pactuada com os atores necessários, a oferta de cuidados que não estão disponíveis nos SHH. Ainda, 
considerando a perspectiva do cuidado integral e que em muitas regiões do país a acessibilidade é um obstáculo que ocasiona várias implicações para o sucesso da adesão ao tratamento, a elaboração e a implementação de Linhas de Cuidado na Atenção Hematológica favorece a superação dos vazios assistenciais, visto, inclusive, que o atendimento próximo ao local de residência proporciona estabelecimento de vínculo entre o usuário e a equipe de saúde, promovendo uma abordagem mais integral. Na atenção às pessoas com Hemoglopinopatias, essa lógica de cuidado tem refletido na redução da morbimortalidade e no aumento da expectativa de vida para as pessoas com doença Falciforme. (BRASIL, 2006b, 2016)

Apesar da importância da gestão federal no fomento e na orientação das diretrizes para a organização de Linhas de Cuidado na Atenção Hematológica, cabe ressaltar que a conformação e a pactuação dos fluxos de cuidado ocorrem nas instâncias regionais, já que uma determinada região de saúde possui características diversas quanto à composição dos serviços em sua rede. Por esse motivo, o envolvimento dos devidos gestores de serviço e da Secretaria de Saúde do estado torna-se essencial para legitimar as negociações e os acordos dos fluxos estabelecidos. Nesse sentido, recomenda-se, ainda, a aprovação das Linhas de Cuidado nas Comissões Intergestores Regional (CIR) e nas Comissões Intergestores Bipartite (CIB) (BRASIL, 2011), com o intuito não apenas de definir os serviços envolvidos, mas também de pleitear investimentos para a melhoria da atenção.

Por fim, para além da elaboração e definição da Linha de Cuidado, a implementação é etapa importante deste ciclo de políticas públicas, pois é entendida como o "resultado de um processo interativo através do qual uma política, que se mantém em formulação durante um tempo considerável, se relaciona com o seu contexto e com as organizações responsáveis por sua implementação". (BAPTISTA; REZENDE, 2011, p. 150) Rua (1998) também coloca os riscos existentes na fase da implementação, pois pode ocorrer distanciamento entre a demanda que deu origem ao processo e seu atendimento efetivo. Além disso, ressalta que não existe vínculo direto entre a decisão política e a sua implementação.

Os desafios para implementação das Linhas de Cuidado também podem ser considerados os mesmos aos das RAS, já que operam na mesma lógica de integração de serviços, tais como a capacitação das equipes e dos gestores; 
a incipiente estrutura de gestão nas regiões de saúde; a governança e financiamento insuficiente das redes; as deficiências em sistemas de informação e comunicação; o nó crítico da regulação; e a insuficiência da oferta histórica de serviços do SUS em diversos componentes e nas várias regiões do país. (MAGALHÃES JÚNIOR, 2014)

Nesse sentido, considerando os desafios da implementação das Linhas de Cuidado, especialmente no atual cenário econômico do país e considerando as complexidades e peculiaridades da Atenção Hematológica, que ora exigem a concentração de cuidados nos serviços de hematologia e hemoterapia e ora necessitam articulação com outros pontos de atenção das RAS, pressupõem-se que os desafios são amplos desde as fases de elaboração e definição até a de implementação, o que aponta a necessidade do envolvimento permanente de profissionais, gestores e usuários e o alinhamento de múltiplas estratégias técnicas e de gestão visando à melhoria da oferta de cuidados a este público.

\section{Considerações finais}

Embora projetos, estratégias e iniciativas têm sido desenvolvidos visando à implementação de ações integrativas nos demais entes federativos, muitas dificuldades e desafios ainda persistem no cotidiano dos gestores, profissionais e usuários que buscam melhorias para a atenção hematológica e hemoterápica.

O compromisso para a superação das vulnerabilidades programáticas, sociais e individuais presentes na atenção hematológica e hemoterápica é coletivo e exige ainda grandes somas de investimentos material e humano, bem como impõem a necessidade tanto de ações e de resultados imediatos, quanto de longo prazo. Portanto, o reconhecimento e análise dos problemas, bem como, a priorização, o desenho e execução das ações é responsabilidade dos diferentes atores, não sendo o esforço restrito individualmente ao gestor, profissional ou usuário.

Resgatando a importância da inclusão e permanência da política na agenda de governo, bem como, o desenvolvimento das propostas e iniciativas/ ações voltadas para a hemoterapia e atenção hematológica e a necessidade de avaliação que deve contemplar o esforço para a integração das ações e serviços na rede de atenção, as discussões não se esgotam, ao contrário, este 
capítulo provoca reflexões e ousa estimular e motivar práticas transformadoras da realidade que promovam a superação da fragmentação da atenção aos usuários do SUS e dos desafios da gestão em saúde.

\section{Referências}

AGÊNCIA NACIONAL DE VIGILÂNCIA SANITÁRIA (Brasil). Resolução nº 10, de 23 de janeiro de 2004. Aprova as diretrizes para uso de Plasma Fresco Congelado - PFC e de Plasma Vírus Inativo. Diário Oficial [da] República Federativa do Brasil, Brasília, DF, 26 jan. 2004. Disponível em: <http://redsang. ial.sp.gov.br/site/docs_leis/rs/rs10.pdf>. Acesso em: 29 jan. 2016.

AGÊNCIA NACIONAL DE VIGILÂNCIA SANITÁRIA (Brasil). Resolução ${ }^{\circ}$ 151, de 21 de agosto de 2001. Aprova o Regulamento Técnico sobre Níveis de Complexidade dos Serviços de Hemoterapia. Diário Oficial [da] República Federativa do Brasil, Brasília, DF, 22 ago. 2001.

AVALIAÇÃO sanitária dos serviços de hemoterapia - 2014. Boletim Anual de Avaliação Sanitária em Serviços de Hemoterapia, Brasília, DF, n. 7, nov. 2015. Disponível em: <http://portal.anvisa.gov.br/documents/33840/2817158/ 7\%C2\%BA+Boletim+Anual+de+Avalia\%C3\%A7\%C3\%A3o+Sanit\%C3\%Alria +em+Servi\%C3\%A7os+de+Hemoterapia+2015/884eafal-baeb-47d9-9061e761lddle274>. Acesso em: 6 maio 2016.

BAPTISTA, T. W. de F.; REZENDE, M. de. A ideia de ciclo na análise de políticas públicas. In: MATTOS, R. A. de; BAPTISTA, T. W. de F. (Org.). Caminhos para análise das políticas de saúde. Porto Alegre: Rede Unida, 2011. p. 138-172. Disponível em: <http://historico.redeunida.org.br/editora/ biblioteca-digital/serie-interlocucoes-praticas-experiencias-e-pesquisasem-saude/caminhos-para-analise-das-politicas-de-saude-pdf $>$. Acesso em: 17 maio 2016.

BARCA, D. A. A. V. Política nacional de sangue, componentes e hemoderivados no Brasil. In: BRASIL. Ministério da Saúde. Técnico em hemoterapia: livro texto. Brasília, DF: 2013. p. 37-45. Disponível em: <http:// bvsms.saude.gov.br/bvs/publicacoes/tecnico_hemoterapia_livro_texto.pdf $>$. Acesso em: 28 mar. 2014.

BASTOS, M. S.; SOUZA, M. K. B. Perfil de agências transfusionais no estado do Pará: adequação à legislação hemoterápica. Salvador, 2014.

BRASIL. Decreto $n^{\circ} 3.990$, de 30 de outubro de 2001. Regulamenta o art. 26 da Lei $n^{\circ} 10.205$, de 21 de março de 2001, que dispõe sobre a coleta, processamento, estocagem, distribuição e aplicação do sangue, seus 
componentes e derivados, e estabelece o ordenamento institucional indispensável à execução adequada dessas atividades. Diário Oficial [da] República Federativa do Brasil, Poder Executivo, Brasília, DF, 31 out. 2001a. Seção 1, p. 1.

BRASIL. Decreto $\mathrm{n}^{\circ} 7.508$, de 28 de junho de 2011. Regulamenta a Lei $\mathrm{n}^{\circ}$ 8.080, de 19 de setembro de 1990, para dispor sobre a organização do Sistema Único de Saúde - SUS, o planejamento da saúde, a assistência à saúde e a articulação interfederativa, e dá outras providências. Diário Oficial [da] República Federativa do Brasil, Poder Executivo, Brasília, DF, 29 jun. 2011. Seção 1, p. 1.

BRASIL. Lei ${ }^{\circ}$ 1.075, de 27 de março de 1950. Dispõe sôbre doação voluntária de sangue. Coleção de Leis da República Federativa do Brasil, Brasília, DF, v. 3, p. 142, abr. 1950.

BRASIL. Lei ${ }^{\circ}$ 4.701, de 28 de junho de 1965. Dispõe sobre o exercício da atividade hemoterápica no Brasil e dá outras providências. Diário Oficial [da] República Federativa do Brasil, Poder Legislativo, Brasília, DF, 9 jul. 1965. Seção 1, p. 6450. Disponível em: <http://www.planalto.gov.br/ccivil_03/leis/ L4701.htm>. Acesso em: 10 nov. 2015.

BRASIL. Lei n ${ }^{\circ} 8.080$, de 19 de setembro de 1990. Dispõe sobre as condições para a promoção, proteção e recuperação da saúde, a organização e o funcionamento dos serviços correspondentes e dá outras providências. Diário Oficial [da] República Federativa do Brasil, Poder Legislativo, Brasília, DF, 20 set. 1990. Seção 1, p. 18055.

BRASIL. Lei 10.205, de 21 de março de 2001. Regulamenta o § $4^{\circ}$ do art. 199 da Constituição Federal, relativo à coleta, processamento, estocagem, distribuição e aplicação do sangue, seus componentes e derivados, estabelece o ordenamento institucional indispensável à execução adequada dessas atividades, e dá outras providências. Diário Oficial [da] República Federativa do Brasil, Poder Legislativo, Brasília, DF, 22 mar. 2001b. Seção 1, p. 1. Disponível em: <http://www.planalto.gov.br/ccivil_03/leis/leis_2001/ 110205.htm>. Acesso em: 10 nov. 2015.

BRASIL. Ministério da Saúde. Portaria n ${ }^{\circ}$ 364, de 6 de maio de 2014. Aprova o Protocolo de Uso de Profilaxia Primária para Hemofilia Grave._Diário Oficial [da] República Federativa do Brasil, Brasília, DF, 7 maio 2014a. Seção 1, p. 46.

BRASIL. Ministério da Saúde. Portaria n ${ }^{\circ}$ 399, de 22 de fevereiro de 2006. Divulga o Pacto pela Saúde 2006 - Consolidação do SUS e aprova as Diretrizes Operacionais do Referido Pacto. Diário Oficial [da] República Federativa do Brasil, Brasília, DF, 23 fev. 2006a. Seção 1, p. 43. Disponível em: 
<http://bvsms.saude.gov.br/bvs/saudelegis/gm/2006/prt0399_22_02_2006. html>. Acesso em: 20 jan. 2016.

BRASIL. Ministério da Saúde. Portaria ${ }^{\circ}$ 478, de 16 de junho de 2014. Aprova o Protocolo de Uso de Indução de Imunotolerância para Pacientes com Hemofilia A e Inibidor. Diário Oficial [da] República Federativa do Brasil, Brasília, DF, 17 jun. 2014b. Seção 1, p. 70.

BRASIL. Ministério da Saúde. Portaria $n^{\circ}$ 822, de 6 de junho de 2001. Institui, no âmbito do Sistema Único de Saúde, o Programa Nacional de Triagem Neonatal. Diário Oficial [da] República Federativa do Brasil, Brasília, DF, 7 jun. 2001c. Seção 1, p. 33. Disponível em: <http://bvsms.saude.gov.br/bvs/ saudelegis/gm/2001/prt0822_06_06_2001.html>. Acesso em: 6 maio 2016.

BRASIL. Ministério da Saúde. Portaria n 951, de 10 de maio de 1996. Institui grupo de trabalho com a finalidade de elaborar o Programa Nacional de Anemia Falciforme. Diário Oficial [da] República Federativa do Brasil, Brasília, DF, 13 maio 1996.

BRASIL. Ministério da Saúde. Portaria n ${ }^{\circ}$ 1.391, de 16 de agosto de 2005. Institui no âmbito do Sistema Único de Saúde, as diretrizes para a Política Nacional de Atenção Integral às Pessoas com Doença Falciforme e outras Hemoglobinopatias. Diário Oficial [da] República Federativa do Brasil, Brasília, DF, 18 ago. 2005. Seção 1, p. 40. Disponível em: <http://bvsms.saude.gov. br/bvs/saudelegis/gm/2005/prt1391_16_08_2005.html>. Acesso em: 20 jan. 2016.

BRASIL. Ministério da Saúde. Portaria ${ }^{\circ} 4.279$, de 30 de dezembro de 2010. Estabelece diretrizes para a organização da Rede de Atenção à Saúde no âmbito do Sistema Único de Saúde (SUS). Diário Oficial [da] República Federativa do Brasil, Brasília, DF, 31 dez. 2010. Seção 1, p. 88. Disponível em: <http://bvsms.saude.gov.br/bvs/saudelegis/gm/2010/prt4279_30_12_2010. html>. Acesso em: 1 dez. 2014.

BRASIL. Ministério da Saúde. Secretaria de Atenção à Saúde. Departamento de Atenção Especializada e Temática. Doença falciforme: diretrizes básicas da linha de cuidado. Brasília, DF, 2015. 82 p.

BRASIL. Ministério da Saúde. Secretaria de Atenção à Saúde. Departamento de Atenção Especializada e Temática. Guia para implementar avaliações nos serviços de hematologia e hemoterapia na perspectiva do Programa Nacional de qualificação da hemorrede. Brasília, DF, 2016. Disponível em: <http://bvsms. saude.gov.br/bvs/publicacoes/guia_implementar_avaliacoes_servicos_ hematologia.pdf $>$. Acesso em: 13 maio 2016. 
BRASIL. Ministério da Saúde. Secretaria de Atenção à Saúde. Departamento de Atenção Especializada. Manual de anemia falciforme para agentes comunitários de saúde. Brasília, DF, 2006b. (Série A: normas e manuais técnicos). Disponível em: <http://bvsms.saude.gov.br/bvs/publicacoes/ manual_anemia_falciforme_agentes_comunitario.pdf $>$. Acesso em: 17 maio 2016.

BRASIL. Ministério da Saúde. Secretaria de Atenção à Saúde. Departamento de Atenção Especializada. Perfil das coagulopatias hereditárias no Brasil: 2009-2010. 2. ed. Brasília, DF, 2012.

BRASIL. Ministério da Saúde. Secretaria de Atenção à Saúde. Diretoria de Articulação de Redes de Atenção à Saúde. Redes regionalizadas de atenção à saúde: contexto, premissas, diretrizes gerais, agenda tripartite para discussão e proposta de metodologia para apoio à implementação. Brasília, DF, 2008.

CANÇADO, R. D.; JESUS, J. A. A doença falciforme no Brasil. Revista Brasileira de Hematologia e Hemoterapia, [São Paulo], v. 29, n. 3, p. 203-206, 2007.

CÂNDIDO, G. A.; ABREU, A. F de. Os conceitos de redes e as relações interorganizacionais: um estudo exploratório. In: BASTOS, M. S.; SOUZA, M. K. B. Perfil de agências transfusionais no estado do Pará: adequação à legislação hemoterápica. Salvador, 2014.

CAZAL, P. Relatório sobre a organização da hemoterapia no Brasil. [S.l.]: Organização Mundial da Saúde, 1969.

CIOFFI, J. G. M.; MURAO, M. Produção de serviços: o ciclo do sangue e os ambulatórios. In: FUNDAÇÃO CENTRO DE HEMATOLOGIA E HEMOTERAPIA DE MINAS GERAIS. Fundação Hemominas: 1985-2007. Belo Horizonte, 2007. cap. 9, p. 91-156.

FLEURY, S.; OUVERNEY, A. M. Política de saúde: uma política social. In: GIOVANELLA, L. et al. (Org.). Políticas e sistema de saúde no Brasil. 2. ed. rev. e ampl. Rio de Janeiro: Ed. Fiocruz, 2012. cap. 1, p. 25-57.

FRANCO, T. B.; MAGALHÃES JÚNIOR, H. M. A integralidade na assistência à saúde e a organização das linhas de cuidado. In: MERHY, E. E. et al. $O$ trabalho em saúde: olhando e experienciando o SUS no cotidiano. São Paulo: Hucitec, 2004.

GRAMKOW, A. Redes e parcerias organizacionais: a experiência da maricultura catarinense. 2002. 158 f. Dissertação (Mestrado em Administração) Universidade Federal de Santa Catarina, Florianópolis, 2002. 
GUERRA, C. C. C. Fim da doação remunerada de sangue no Brasil faz 25 anos. Revista Brasileira de Hematologia e Hemoterapia, [São Paulo], n. 27, n. 1, p. 1-4, jan./mar. 2005.

HARTZ, Z. M. de A.; CONTANDRIOPOULOS, A.-P. Integralidade da atenção e integração de serviços de saúde: desafios para avaliar a implantação de um "sistema sem muros". Cadernos de Saúde Pública, Rio de Janeiro, v. 20, p. 331336, 2004. Suplemento 2.

HOGAN, V.; GARGARELLA, G. Revisão do Sistema Nacional de Sangue. Brasília, DF, 1997. Relatório destinado ao Ministério da Saúde.

JUNQUEIRA, P. C.; ROSENBLIT, J.; HAMERSCHLAK, N. História da hemoterapia no Brasil. Revista Brasileira de Hematologia e Hemoterapia, [São Paulo], v. 27, n. 3, p. 201-207, 2005.

LANDSTEINER, K. Zur Kenntnis der anti fermentativen, lytischen und agglutinierenden Wirkungen des Blutserums und der Lymphe. Zentralbl Bakteriol, [S.1.], n. 27, p. 357- 362, 1900.

MAGALHÃES JÚNIOR, H. M. Redes de atenção à saúde: rumo à integralidade. Revista Divulgação em Saúde para Debate, Rio de Janeiro, n. 52, p. 15-37, out. 2014. Disponível em: <http://cebes.org.br/site/wp-content/uploads/2014/12/ Divulgacao-52.pdf $>$. Acesso em: 18 maio 2016.

MALTA, D. C.; MERHY, E. E. O percurso da linha do cuidado sob a perspectiva das doenças crônicas não transmissíveis. Interface: comunicação, saúde e educação, Botucatu, v. 14, n 34, p. 593-605, jul./set. 2010.

MÁXIMO, C. A política de atenção integral à pessoa com doença falciforme no estado do Rio de Janeiro e os desafios da descentralização. 2009. $104 \mathrm{f}$. Dissertação (Mestrado em Saúde Publica) - Escola Nacional de Saúde Pública, Fundação Oswaldo Cruz, Rio de Janeiro, 2009. Disponível em: <https://www.arca.fiocruz.br/bitstream/icict/5267/2/1168.pdf>. Acesso em: 7 jan. 2016.

MELO, H. T. Mapeamento do ordenamento jurídico da política nacional de sangue e da regulamentação técnica na área do sangue e derivados. 2015. 102 f. Dissertação (Mestrado em Medicina) - Faculdade de Medicina de Ribeirão Preto, Universidade de São Paulo, Ribeirão Preto, 2015. Disponível em: $<$ http://www.teses.usp.br/teses/disponiveis/17/17155/tde-22062015-215957/ pt-br.php>. Acesso em: 26 jan. 2016.

MENDES, E. V. As redes de atenção à saúde. 2. ed. Brasília, DF: Organização Pan-Americana da Saúde, 2011. 
MENDES, E. V. As redes de atenção à saúde. Ciência \& Saúde Coletiva, Rio de Janeiro, v. 15, n. 5, p. 2297-2305, 2010.

MERHY, E. E. A perda da dimensão cuidadora na produção da saúde: uma discussão do modelo assistencial e da intervenção no seu modo de trabalhar a assistência. In: CAMPOS, C. R. et al. (Org.). Sistema Único de Saúde em Belo Horizonte: reescrevendo o público. Belo Horizonte: Xamã, 1998. p. 103-120.

NORONHA, J. C.; LIMA, L. D.; MACHADO, C. V. O Sistema Único de Saúde SUS. In: GIOVANELLA, L. et al. (Org.). Políticas e sistema de saúde no Brasil. 2. ed. rev. e ampl. Rio de Janeiro: Ed. Fiocruz: Cebes, 2012. cap. 12, p. 365-393.

PAIM, J. S. Políticas de saúde no Brasil. In: ROUQUAYROL, M. Z.; ALMEIDA FILHO, N. de. Epidemiologia \& saúde. 6. ed. Rio de Janeiro: Medsi, 2003. p. 587-603.

PINTO, I. C. M.; VIEIRA-DA-SILVA, L. M.; BAPTISTA, T. V. F. Ciclo de uma política pública de saúde: problematização, construção da agenda, institucionalização, formulação, implementação e avaliação. In: PAIM, J. S.; ALMEIDA FILHO, N. de. Saúde coletiva: teoria e prática. Rio de Janeiro: MedBook, 2014. cap. 6, p. 69-81.

PUGIN, S. R.; NASCIMENTO, V. B. do. Principais marcos das mudanças institucionais no setor saúde (1974-1996). 1996. (Série didática, n. 1). Disponível em: <http://www.cedec.org.br/files_pdf/DIDATIl.pdf $>$. Acesso em: 7 jan. 2016.

RIBEIRO, C. M. F. A hemoterapia no Brasil até 1980 e a criação dos hemocentros públicos nacionais. In: FUNDAÇÃO CENTRO DE HEMATOLOGIA E HEMOTERAPIA DE MINAS GERAIS. Fundação Hemominas: 1985-2007. Belo Horizonte, 2007. cap. 2, p. 25-36.

RUA, M. G. Análise de políticas públicas: conceitos básicos. In: RUA, M. das G.; CARVALHO, M. I. V. de. O estudo da política: tópicos selecionados. Brasília, DF: Paralelo 15, 1998. Disponível em: <http://franciscoqueiroz.com.br/portal/ phocadownload/gestao/rua\%20maria\%20_\%20analisedepoliticaspublicas. pdf $>$. Acesso em: 23 jan. 2016.

SAMPAIO, D. D. A. Cenário político, social e cultural da hemoterapia no Brasil. In: BRASIL. Ministério da Saúde. Técnico em hemoterapia: livro texto. Brasília, DF: 2013. p. 7-18. Disponível em: <http://bvsms.saude.gov.br/bvs/ publicacoes/tecnico_hemoterapia_livro_texto.pdf $>$. Acesso em: 28 mar. 2014.

SANTOS, L. A. de C.; MORAES, C.; COELHO, V. S. P. A hemoterapia no Brasil de 64 a 80. Physis: Revista de Saúde Coletiva, Rio de Janeiro, v. 1, n. 1, p. 161$182,1991$. 
SARAIVA, J. C. P. A história da hemoterapia no Brasil. Revista Brasileira de Hematologia e Hemoterapia, [São Paulo], v. 27, n. 3, p. 153-158, 2005.

SILVA, K. F. N.; SOARES, S.; IWAMOTO, H. H. A prática transfusional e a formação dos profissionais de saúde. Revista Brasileira de Hematologia e Hemoterapia, [São Paulo], v. 31, n. 6, p. 421-462, dez. 2009.

SOUZA, L. E. P. F.; VIANA, A. L. D’A. Gestão do SUS: descentralização, regionalização e participação social. In: PAIM, J. S.; ALMEIDA FILHO, N. de. Saúde coletiva: teoria e prática. Rio de Janeiro: MedBook, 2014. p. 261-269. 